\title{
Relative seismic shaking vulnerability microzonation using an adaptation of the Nakamura horizontal to vertical spectral ratio method
}

\author{
Michael L TURNBULL \\ Central Queensland University, Faculty of Business and Informatics, Bundaberg DC, Queensland, Australia. \\ e-mail: M.Turnbull.cqu.edu.au
}

\begin{abstract}
An alternative seismic shaking vulnerability survey method to computational intensive theoretical modelling of site response to earthquake, and time consuming test versus reference site horizontal ratio methods, is described. The methodology is suitable for small to large scale engineering investigations. Relative seismic shaking vulnerability microzonation using an adaptation of the Nakamura horizontal to vertical spectral ratio method provides many advantages over alternative methods including: low cost; rapid field phase $\left(100 \mathrm{~km}^{2}\right.$ can easily be covered by a single operator in 5 days); low and flexible instrumentation requirements (a single seismometer and data logger of almost any type is required); field data can be collected at any time during the day or night (the results are insensitive to ambient social noise); no basement rock reference site is required (thus eliminating trigger synchronisation between reference and multiple test site seismographs); rapid software aided analysis; insensitivity to ground-shaking resonance peaks; ability to compare results obtained from non-contiguous survey fields. The methodology is described in detail, and a practical case study is provided, including mapped results. The resulting microzonation maps indicate the relative seismic shaking vulnerability for built structures of different height categories within adjacent zones, with a resolution of approximately $1 \mathrm{~km}$.
\end{abstract}

\section{Introduction}

There are two broad categories of methods used in characterising the horizontal response of a particular surface site to incident seismic energy - theoretical modelling and empirical measurement.

In theoretical modelling basic physical theory and knowledge of the site conditions (e.g., geology, topography and boundary conditions) are used to create a mathematical model of the site. The solution(s) to these mathematical models require extensive computational capability and expert knowledge of computer program and numerical methods. Models of one, two and three dimensions have been produced (c.f., Coutel and Mora 1998). Theoretical modelling depends on detailed physical knowledge of the site of interest. Such detailed knowledge is rarely available in practice. Assumptions have to be made which reduce confidence in the modelled results. The formulation and solution of the model is time consuming and expensive.

The empirical measurement category of site response characterisation relies on direct measurement of horizontal ground movement amplification within the area of interest. The ground movement at a matrix of sites within the area is measured and the results are used to produce a static map depicting the relative seismic shaking vulnerability present at adjacent sites. Two methods that fit into this category are the test/reference site spectral ratio method and the single site horizontal/vertical spectral ration method.

Keywords. Microzonation; earthquake hazard; Nakamura; ground motion; geophysics; seismology; natural hazards. 
In contrast with the theoretical modelling method, the empirical measurement methods do not rely on extensive computing power. Although the data collection and some of the analysis require very modest computing facilities, much of the result presentation can be done manually if necessary. This makes the method particularly suited for developing countries and small institutions.

\subsection{Two site spectral ratio method}

This method relies on the presence, within the area of interest, of a reference site that has the response characteristics of basement bedrock. Such a reference site may be obtained by boring a hole down to the bedrock and installing an instrument at the bottom of the hole; or, preferably, by locating an instrument on a nearby outcrop of solid basement rock. The quality of results obtained using this method is dependent on the characteristics of the reference site and considerable care must be taken in choosing a suitable reference site (Steidl et al 1996).

During the measurement period two instruments are deployed, one at the site of interest and one at the reference site. The instruments are triggered simultaneously, or within an overlapping time period, to measure ground movement at both sites stimulated by a common seismic energy source. The horizontal time series data from each site is converted by Fourier transform techniques to an amplitude or power spectrum and the ratio of the site spectrum to the reference spectrum is produced. The site to reference ratio is a direct measure of the horizontal ground movement amplification at the site of interest.

If the reference site is the actual basement bedrock under the measurement site then the ratio is equivalent to the basement to surface layer, frequency dependent horizontal transfer function $T_{B S}(f)$; defined as follows, where $H_{S}(f)$ is the horizontal spectrum at the surface layer, and $H_{B}(f)$ is the horizontal spectrum at the basement layer:

$$
T_{B S}(f)=\frac{H_{S}(f)}{H_{B}(f)} .
$$

This method has been employed using various seismic energy sources including: earthquake $\mathrm{S}$ waves (c.f., Chávez-García et al 1997; Coutel and Mora 1998; Wen et al 1995a, b); P waves (c.f., Lachet et al 1996); earthquake coda (c.f., Field 1996); ambient seismic noise (c.f., Seht and Wohlenberg 1999; Konno and Ohmachi 1998; Coutel and Mora 1998; Lachet et al 1996; Chávez-García et al 1996; McCue and Boreham 1996; Field 1996; Ferritto 1996; Seekins et al 1996; Clithero and Taber 1995; Field and Jacob 1995; Somerville et al 1993; Kagami et al 1986); and high explosive blasts (c.f., Malagnini et al 1996).

There has been considerable interest in using this method employing ambient seismic noise as the source. This technique has the obvious advantage that the instrumentation does not need to be put in place over long periods to observe actual earthquake events. It also has the distinct advantage of not requiring invasive drilling and blasting. All that is needed is for the reference instrument to be deployed and the site instrument to be then transported from station to station in order to collect matching pairs of ambient noise recordings. If numerous sites are to be occupied, however, there is still considerable time involved. There is also the logistic difficulty of simultaneous triggering of the instruments to be considered.

The two site spectral ratio method has been used in a limited capacity for microzonation where relatively few sites have been used (c.f., Lachet et al 1996; McCue and Boreham 1996; Clithero and Taber 1995; Sommerville et al 1993; Darragh and Shakal 1991). It has had restricted application in large-scale high-resolution microzonation except for one notable exception in Perth, western Australia (Gaull et al 1995). In this latter study six instruments were used simultaneously; five at basin stations, and one at the reference site. The five basin stations were deployed to take late night simultaneous readings over two nights. Over 100 sites were occupied using $3 \mathrm{~km}$ grid spacing, implying that the data collection would have taken more than 40 days.

The method has the disadvantage that the presence of noise generated by localised social movement (cars, trucks, trains, pedestrians, etc.), which does not equally affect the site and reference instrument, tends to produce results which are not characteristic of the site of interest, but are characteristic of the energy source. Consequently the periods during which the technique can be employed are limited to those times of the night when social noise is at a minimum (usually in the hours between midnight and dawn). It also has the disadvantage that it cannot be employed in areas where a suitable reference site is not available.

\subsection{Single site spectral ratio method}

If it can be shown that the vertical ground motion at a site of interest is characteristic of the basement bedrock motion at that site, then the horizontal to vertical ground motion ratio will correspond to the site to reference ratio measure of horizontal ground motion amplification. The single site spectral ratio method of characterising site response relies on this condition being approximated. In this method, 
the simultaneous horizontal and vertical ground motion is measured using a single multi-axis instrument. The amplitude or power spectrum of the horizontal and the vertical data are determined using standard Fourier transform techniques, and the ratio of the horizontal to vertical spectra is produced. This method is generally referred to as the Horizontal to Vertical Spectrum Ratio (HVSR) method.

\subsection{The Nakamura method}

In 1989, Yutaka Nakamura used the single site HVSR method to study responses at socially noisy sites, using ambient seismic noise sources, and found that the results resembled the transfer functions for horizontal motion in the surface layers. Nakamura showed that, for a relatively wide frequency range, localised noise sources consisting of mainly Rayleigh waves were cancelled out during the horizontal to vertical ratio process. His reasoning was as follows.

Nakamura noted in the basement to surface layer, frequency dependent horizontal transfer function $T_{B S}(f)$ (see equation 1) that $H_{S}(f)$ is readily affected by locally generated social noise, which mainly consists of Rayleigh waves. Nakamura also noted that the vertical spectrum at the surface layer $V_{S}(f)$ should include the local Raleigh wave contribution, but the basement vertical spectrum $V_{B}(f)$ should not.

Assuming that the surface layer does not amplify the vertical ground motion, the effect of the local Rayleigh waves on the incident microtremor motion within the surface layer can be represented as:

$$
\varepsilon_{S}(f)=\frac{V_{S}(f)}{V_{B}(f)},
$$

where there is a Rayleigh wave contribution, $\varepsilon_{S}(f)$ will be greater than unity and this will converge to unity as the contribution of the local Rayleigh wave decreases; therefore $\varepsilon_{S}(f)$ is greater than or equal to unity at all frequencies.

Assuming that the effect of the local Rayleigh wave on the horizontal and vertical incident motion is equal (i.e., its ellipticity is unity), a modified surface layer horizontal transfer function $T_{B S M}(f)$ may be defined as:

$$
T_{B S M}(f)=\frac{T_{B S}(f)}{\varepsilon_{S}(f)} .
$$

We also define the following ratios:

$$
R_{S}(f)=\frac{H_{S}(f)}{V_{S}(f)}
$$

$$
R_{B}(f)=\frac{H_{B}(f)}{V_{B}(f)},
$$

which allows $T_{B S M}(f)$ to be expressed as:

$$
T_{B S M}(f)=\frac{R_{S}(f)}{R_{B}(f)} .
$$

Nakamura was able to show that the $24 \mathrm{~h}$ averaged horizontal to vertical basement ratio $R_{B}(f)$, for three different measurement sites, was approximately unity over a frequency range from 0.1 to $20 \mathrm{~Hz}$.

Under the condition that $R_{B}(f) \approx 1$ (i.e., the ellipticity of the incident waves in the basement material is approximately unity), equation (6) reduces to

$$
R_{N}(f)=T_{B S M}(f) \approx R_{S}(f)=\frac{H_{S}(f)}{V_{S}(f)},
$$

where $R_{N}(f)$ is referred to as the Nakamura spectral ratio.

It can be seen that the Nakamura spectral ratio is the basement to surface layer, frequency dependent horizontal transfer function $T_{B S}(f)$, modified to allow for the possible presence of a Rayleigh wave generated locally within the surface layer. Under the assumption that the ellipticity of the local Rayleigh wave is unity, the effect of the local Rayleigh wave is cancelled out of the modified horizontal transfer function.

In reality ideal cancellation does not occur and the modified horizontal transfer function does not reproduce the original horizontal transfer function faithfully. Spectra produced using the Nakamura ratio are similar to, but demonstrably different from, those produced using the horizontal transfer function. This may be due to several factors some of which are suggested below.

- The locally generated noise may not be purely Rayleigh waves.

- The ellipticity of the local noise waves in the surface layer may not be unity.

- The ellipticity of the incident waves in the basement layer may not be (indeed probably would not be) unity.

- The ellipticity of the local noise and the incident waves may vary over time and space depending on the nature of the local noise and the incident waves.

The Nakamura method is a special application of the HVSR method. It has the particular advantage of providing an efficient and cheap means of collecting data from numerous sites, within a short space 
of time, at any time during the day. Support for the assumption that $R_{B}(f) \approx 1$, or at least that the average over the frequency range of interest is approximately unity, has been reported by later researchers (c.f., Somerville et al 1993; Lermo and Chávez-García 1993, 1994; Schlindwein and Koch 2003).

Over the past decade the Nakamura method has been used in numerous site response characterisation and microzonation studies (c.f., Clithero and Taber 1995; Lachet et al 1996; Milana et al 1996; Seekins et al 1996; Field 1996; Konno and Ohmachi 1998; Jones et al 1998; Cuthbertson et al 1998; Michael-Leiba and Jensen 1999; Schlindwein and Koch 2003; Bragato and Slejko 2005; Drouet et al 2005; Ferretti et al 2007). A summary of microzonation surveys carried out within Australia up to the end of 1999 is provided by Jensen (2000).

Several studies have been carried out to compare the results of the Nakamura method with those obtained by other methods, including the general HVSR and reference site methods. Some studies have reported adverse findings (c.f., Malagnini et al 1996), while numerous others indicate that the Nakamura method is valid within certain constraints (c.f., Lermo and Chávez-García 1993, 1994; Clithero and Taber 1995; Field and Jacob 1995; Chávez-García et al 1996, 1997; Dravinski et al 1996; Field 1996; Lachet et al 1996; Theodulidis et al 1996; Seekins et al 1996; Coutel and Mora 1998; Dimitriu et al 1998; Schlindwein and Koch 2003; Bragato and Slejko 2005; Drouet et al 2005; Ferretti et al 2007).

It is now generally recognised (Chávez-García et al 2007) that the Nakamura method adequately identifies the fundamental resonance peak of a site within reasonable error bounds, but is incapable of identifying higher orders of resonance. Similarly, whilst this paper demonstrates that the spectra produced using the method can be used to quantify relative hazard between adjacent sites, they are incapable of indicating the absolute ground motion amplification of a given site.

\section{A methodology for deriving Nakamura spectra from microseismograms}

\subsection{Length of data collection}

Although Nakamura (1989) continuously monitored each site for up to 30 hours, only datasets of 2048 points, or about 20 seconds of data were used for analysis purposes. Kagami et al (1986) monitored each site for 15 minutes, but only sections of 1024 datum points were used for analysis. In carrying out their microtremor study of Newcastle, Somerville et al (1993) took six series of 33-second readings at 125 samples per second at each site. From these recordings subsets of 2000 data were used for analysis.

For data collection at test sites the author chose to record for 2 to 2.5 minutes at a sampling rate of 100 samples per second (Turnbull 2001). This provided a total of from 12,000 to 15,000 data points from each site for analysis purposes.

\subsection{Size and conditioning of analysis dataset}

The size and numbers of the datasets used by past investigators vary considerably. Similarly, the conditioning techniques sometimes applied to the time series data prior to performing the Fourier transform on it varied considerably.

Michael Winter (Pers. Com. 1999), while a postgraduate student studying at the Queensland University Advanced Centre for Earthquake Studies (QUAKES) used numerous analysis routines over an approximate three-year period to perform single and double site spectral analysis of field data collected for microzonation within the greater Brisbane metropolitan area. He employed a variety of time series data conditioning techniques including:

- cosine tapering,

- linear tapering,

- overlapping of data windows,

- demeaning and detrending,

- high and low pass filtering, and

- zero filling of incomplete datasets.

From comments included in his software source code, and from personal conversations the author had with him, Winter was of the opinion that preconditioning of the time series data has little or no effect on the appearance of the resulting spectral ratios. This has also been the author's personal experience. As long as the size of the dataset is sufficient, preconditioning the time series data by means of any of the above techniques produces no appreciable difference to the resultant spectral ratios.

\subsubsection{Multiple windowing}

Figures 1 and 2 each show comparisons of three ground motion spectra calculated from single window time series datasets obtained from the same sites at different times. Figure 1 shows spectra obtained from the site designated AAB001 during three separate data collection episodes, designated BBGA, BBGC and BBGD. Figure 2 shows spectra obtained from a different site designated ABA001 during three separate data collection episodes, designated BBGB, BBGC and BBGD.

Inspection of the spectra figures 1 and 2 reveals that, whilst the various spectra obtained for the 


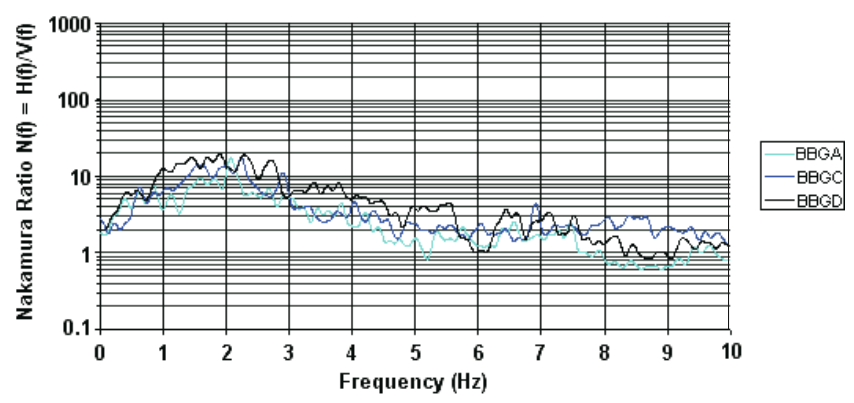

Figure 1. Spectra for site AAB001 derived from timedisplaced datasets.

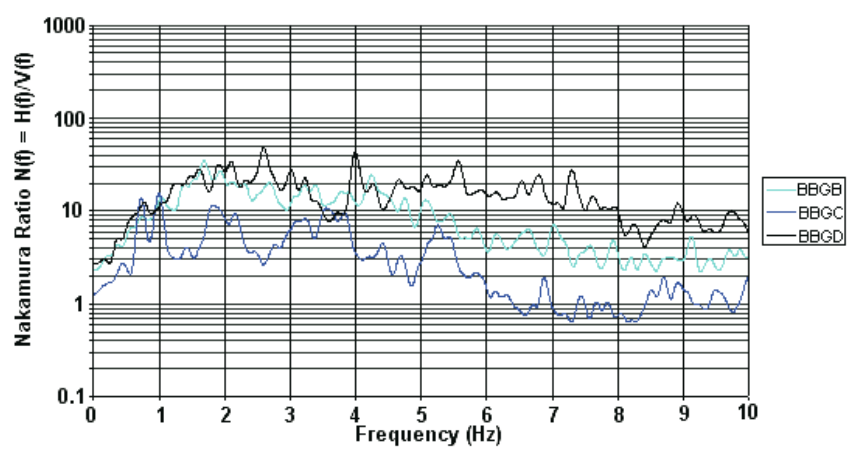

Figure 2. Spectra for site ABA001 derived from timedisplaced datasets.

same site at different times are similar, they contain an obvious degree of difference, due to the natural variability of the microtremor seismic energy sources over time. As a consequence of the variability in the individual spectra it would be undesirable to use any one spectrum for microzonation purposes. The results of that process would, in general, be irreproducible by analysis of data collected at future times and could not be used to monitor for possible changes in the microzonation results over time.

A more statistically valid method would be to combine several spectra obtained at different times by averaging the data points and calculating the standard deviation. This could be done either by collecting time series data by means of several field trips over an extended period of time, or by collecting a single time series reading of sufficient length to provide a number of mutually exclusive contiguous datasets (data windows) of size 1024.

Both of the above methods are equivalent. The only difference is the time lag between the sequential windows of contiguous data. In the former case the time difference may be days or months. In the latter case the time difference is seconds or fractions of a second.

The use of multiple windows from the one time series dataset allows the calculation of the mean and standard deviation for further analysis

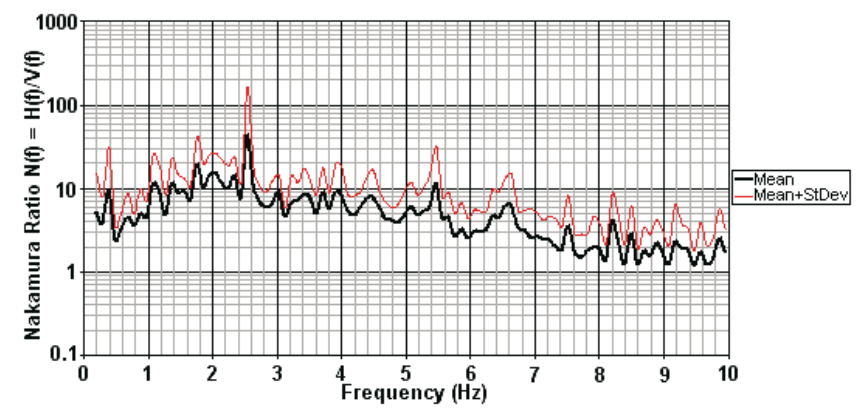

Figure 3. Spectrum derived from multiple data windows.

purposes and ensures the statistical reproducibility of the data. A suitable minimum size for the time series dataset is considered to be 1024 . It would seem that, for microzonation purposes, a single raw data window of sufficient size may be suitable; however, it must be pointed out that the results obtained from a single data window will not be reproducible, and the use of multiple time series windows is a superior method.

Figure 3 depicts a Nakamura spectrum derived by using 10 data windows each consisting of about 100 contiguous data points, extracted from a single seismogram of about 1024 data points in total. The original dataset used to derive the spectrum in figure 3 is the same dataset used to derive the spectrum labelled BBGB in figure 2. However, whilst the individual spectra in figure 2 are in general irreproducible from data obtained at different times, the spectrum in figure 3 can be reproduced, within the calculated statistical bounds, from time series data collected at the site at any time.

\subsubsection{Combining the horizontal datasets}

There are a number of different ways that the horizontal datasets can be combined. They can be combined in the time domain or the frequency domain, and in either case a number of combinational algorithms can be used. The data could be averaged, either by simple arithmetic average, by geometric average, by using the square root of the mean of the squared values (i.e., the RMS or Root Mean Squared value) or by some other more obscure method.

Figures 4, 5, 6 and 7 show ground amplification spectra obtained from the same time series dataset, and with the horizontal components combined by various methods.

Inspection of figure 4, and comparison with figures 5,6 and 7 , reveals that geometric combination of the horizontal components in the time domain produces a spectrum that is substantially different from the other three methods. This is because, in the time domain, the geometric averaging process is equivalent to vector addition. The horizontal 


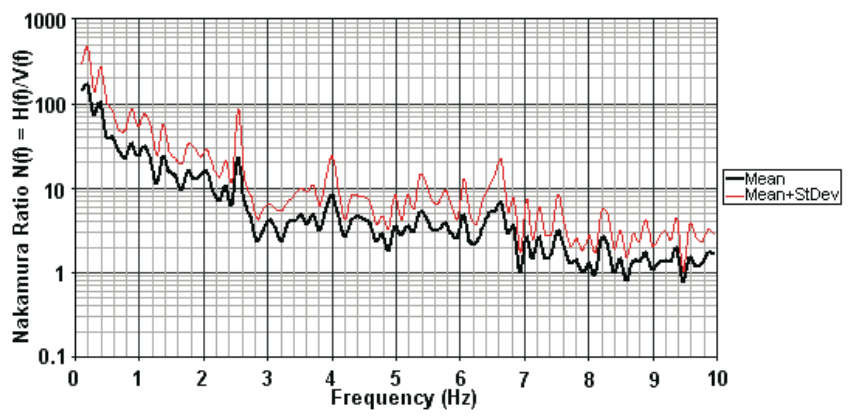

Figure 4. Horizontal combined in time domain by Geometric mean.

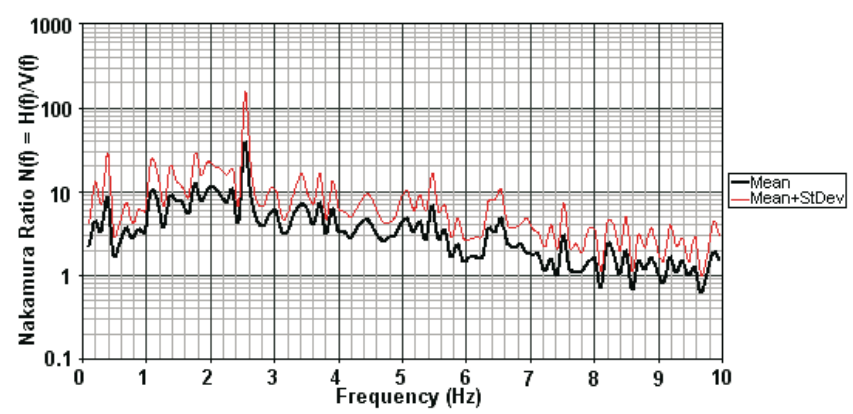

Figure 5. Horizontal combined in time domain by Arithmetic mean.

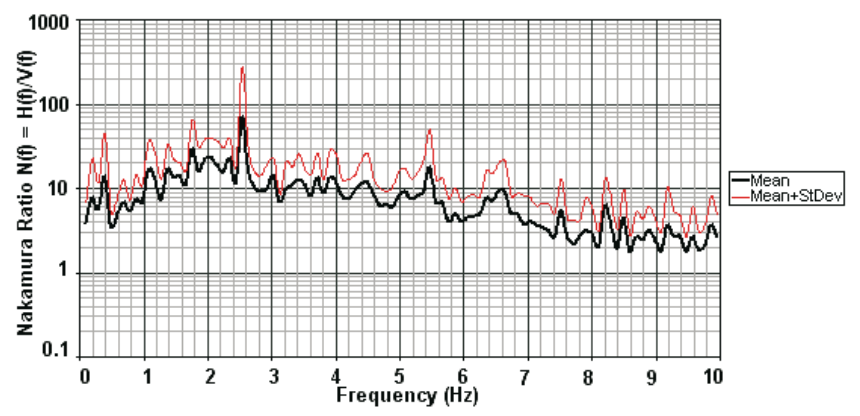

Figure 6. Horizontal combined in frequency domain by Geometric mean.

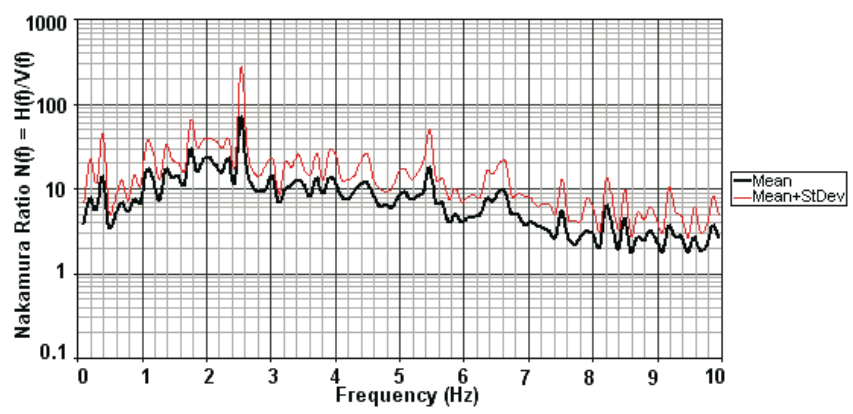

Figure 7. Horizontal combined in frequency domain by Arithmetic mean.

time series datasets are derived from orthogonal orientated sensors. If the motion was being stimulated by a point energy source, then the horizontal signals could be regarded as vector signals and used to determine the azimuth of the source. However, the microtremor sources that produce the ground motion are diffused and variable - tending to be random in nature. Therefore, the horizontal signals cannot be interpreted as a primary indication of the vector direction from which the motional force is coming. Consequently, geometric averaging is inappropriate for combining the horizontal components.

Inspection of figures 5, 6 and 7 shows them to be very similar in appearance. Whilst there are some subtle differences between figure 5 and the other two, those differences are fairly minor. Figure 6 is identical in form to figure 7 except for a vertical displacement of the trace. This is because the geometric average is accentuating the horizontal motion in comparison to the arithmetic average.

For the purposes of microzonation analysis demonstrated out in this paper it was decided to combine the horizontal data in the frequency domain using an arithmetic average.

\subsection{A methodology for using Nakamura spectra to conduct seismic shaking vulnerability microzonation}

\subsubsection{Seismic shaking vulnerability microzonation for engineering purposes}

Within an area that is subject to a common ambient earthquake hazard, it is known that, in general, zones of differing vulnerability exist. This means that, on a microzonal scale, earthquake vulnerability (from the same earthquake hazard) is, in general, different from place to place. The aim of a microzonation survey is to quantify the relative vulnerability of a small zone of interest within a larger regional area.

The relative vulnerability of different classes of buildings, due to their construction techniques and materials, their shape and size, is acknowledged in the building codes (e.g., Australian building code AS1170.4-1993). The Australian building code also allocates earthquake site loading factors $(S)$ based on soil types at the site of interest. Apart from the construction attributes of a building (which can be optimised by engineering design) it is the degree to which the shaking of the ground is transferred to the buildings that determines the relative vulnerability between adjacent sites. It is almost a trivial observation that a building that is more likely to be shaken during an earthquake is at more risk to damage than one that is not. What is not so trivial is devising engineering survey techniques that will quantify the predisposition of a building of a certain class to shake in response to ground movement caused by an earthquake. 
Table 1. Shaking frequency ranges for building classes.

\begin{tabular}{lccc}
\hline Building class & $\begin{array}{c}\text { Range of number } \\
\text { of storeys }\end{array}$ & $\begin{array}{c}\text { Calculated } \\
\text { frequency range }\end{array}$ & $\begin{array}{c}\text { Frequency range } \\
\text { used for analysis }\end{array}$ \\
\hline Low-rise & $1-3$ & $10-3.3 \mathrm{~Hz}$ & $2.9 \leq \mathrm{Hz} \leq 10$ \\
Medium-rise & $4-9$ & $2.5-1.1 \mathrm{~Hz}$ & $1.1 \leq \mathrm{Hz}<2.9$ \\
High-rise & $10+$ & $\leq 1.0 \mathrm{~Hz}$ & $0.5 \leq \mathrm{Hz}<1.1$ \\
\hline
\end{tabular}

Any method of seismic shaking vulnerability microzonation should provide an indication of the degree to which seismic energy is transferred from the foundations of a building to the building structure. The Australian building code (SAA 1993(a) and 1993(b)) AS1170.4-1993 quantifies this degree of energy transfer by specifying a range of site loading factors $(S)$ varying from 0.67 for rock foundations to 2.0 for the deepest, softest soils. This scale of site factors recognises the propensity for deeper, softer soils to exhibit greater ground movement than shallower, denser materials when subjected to seismic shaking. However, the Australian building code, as is common in building codes in many countries, makes no allowance for resonant ground movement amplification observed in some areas.

By using actual site seismic shaking amplification spectra for the sites of interest this deficiency can be addressed.

\subsubsection{Microzonation using generalised natural shaking frequency of a built structure}

All building structures have a natural shaking frequency. If a building is subjected to seismic shaking which corresponds with its natural shaking frequency then it will absorb more energy, and will shake more violently than if the seismic energy was concentrated at some other frequency.

For the purposes of microzonation in this paper it is assumed that the generalised natural shaking frequency $\left(f_{N}\right)$, of a building with $N$ stories, is approximated by equation (8) (c.f., Michael-Leiba and Jensen 1999):

$$
f_{N}[H z] \approx \frac{10}{N}
$$

Three classes of building will be considered in this study; low-rise ( 1 to 3 storeys), medium-rise (4 to 9 storeys), and high-rise (10 or more storeys). Table 1 lists the range of shaking frequencies relevant to the proposed building classes.

Analysis of a site's seismic response spectrum can provide an indication of the relative distribution of seismic energy within the ranges of frequency indicated in table 1 . The lower frequency range for high-rise buildings was set at $0.5 \mathrm{~Hz}$ because that corresponds to a 20 -storey building, which was considered sufficient for the purposes of this study. Figure 8 displays a typical site response spectrum and the associated frequency ranges of interest. In figure 8, the frequency axis has been displayed in logarithmic form to accentuate the lower frequency ranges which on a linear scale would be much narrower in display width.

In determining the relative energy content in any particular frequency range, from one site response spectrum to the next, it is sufficient to use the average amplitude of the measure of ground movement amplification (the pseudo gain). Within any given set of site response spectra, the pseudo gain for each frequency range will vary across the range that includes the natural shaking frequency of structures built on that site. The site that exhibits the largest average pseudo gain within a particular frequency range will present the greatest seismic shaking vulnerability to buildings of the associated class within the data collection area.

Depending on the intended use of the microzonation results the relative vulnerabilities may be presented as numerical values over an arbitrary range, or by qualitative descriptions.

In conformity with the AS1170.4-1993 site factor allocations $(S)$, following analysis of the site response spectra for each building category, the author has devised an empirical formula for allocation of arbitrary (but consistent) microzonation site factors $\left(S_{M}\right)$, based on a partitioning of the pseudo gain $(G)$ at each site in relation to the maximum pseudo gain $\left(G_{\text {Max }}\right)$ of all sites within the microzonation area. The microzonation site factors $\left(S_{M}\right)$ determined by this method are listed in table 2 .

It should be noted that the microzonation site factors $\left(S_{M}\right)$ are not intended to override the AS1170.4-1993 site factors $(S)$. A conservative approach should be maintained in using the microzonation site factors to supplement a building code. The microzonation information should always be used in conjunction with the building code, and not in isolation. In all instances the higher of the site factors obtained from the joint application of the building code and the microzonation results should be used. 


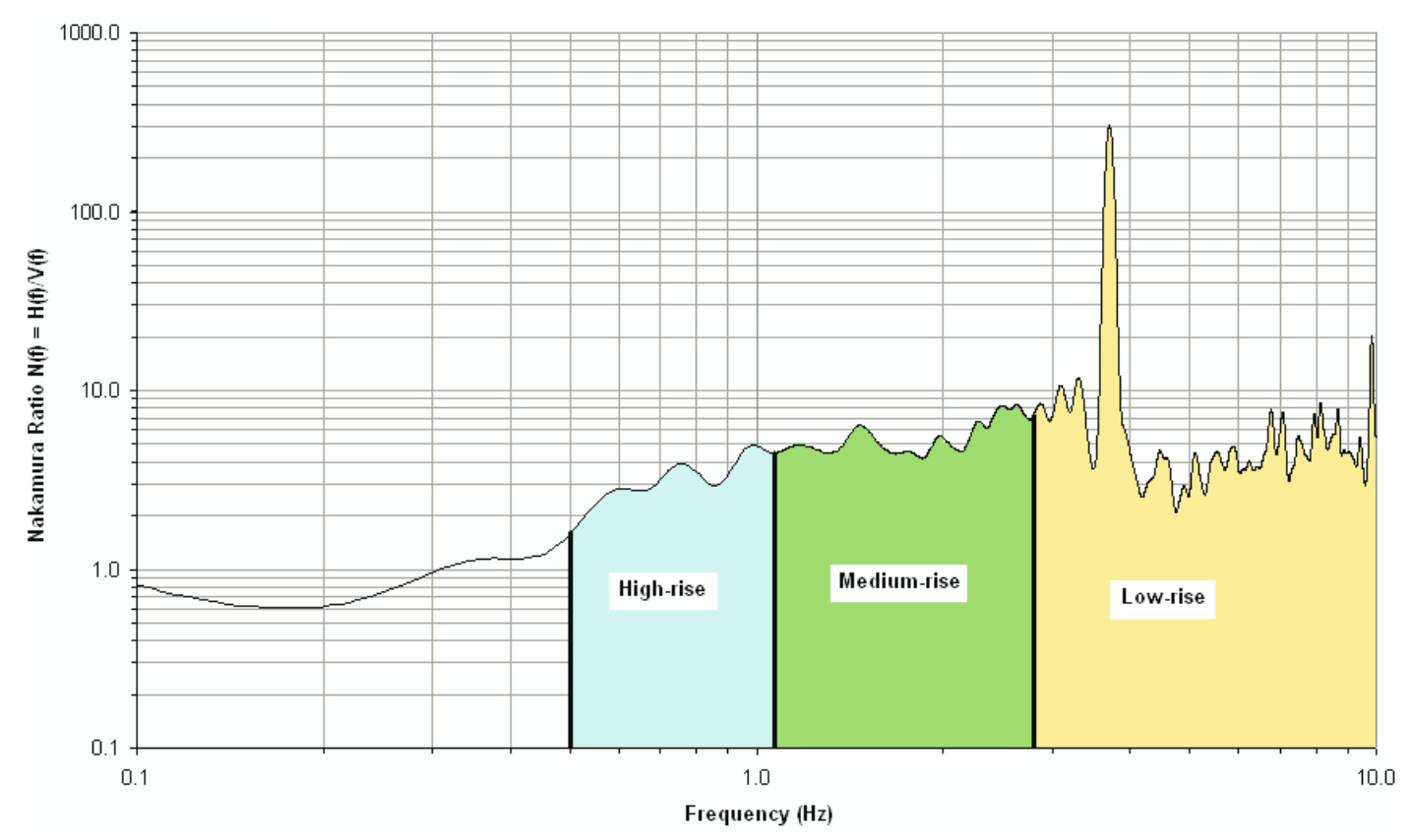

Figure 8. Shaking frequency ranges for building classes.

Table 2. Microzonation site factor allocations.

\begin{tabular}{lc}
\hline $\begin{array}{l}\text { Relationship of the pseudo gain }(G) \text { within the frequency range } \\
\text { of interest at a particular site, to the maximum pseudo gain }\end{array}$ & $\begin{array}{c}\text { Microzonation } \\
\text { site factor } \\
\left(G_{\text {Max }}\right) \text { within the same frequency range at all sites }\end{array}$ \\
\hline$G<1.0$ & 0.67 \\
$1.0 \leq G<\left(G_{M}\right)$ & 1.00 \\
$\left(G_{\text {Max }} * 0.25\right) \leq G<\left(G_{\text {Max }} * 0.50\right)$ & 1.25 \\
$\left(G_{\operatorname{Max}} * 0.50\right) \leq G<\left(G_{\operatorname{Max}} * 0.75\right)$ & 1.50 \\
$\left(G_{\operatorname{Max}} * 0.75\right) \leq G \leq G_{\text {Max }}$ & 2.00 \\
\hline
\end{tabular}

\subsection{Microzonation of Bundaberg city using Nakamura spectra - A case study}

\subsubsection{The seismic setting of Bundaberg city}

Bundaberg is situated on the Burnett River, about 20 to $30 \mathrm{~km}$ from its mouth, in sedimentary deposits confined in a basin bounded by outcropping of bedrock consisting chiefly of coal measures. The basin is filled primarily with Tertiary fluvial deposits. The unconsolidated deposits range in depth from 15 to $70 \mathrm{~m}$ within the microzonation survey area.

The current Australian earthquake loading code, AS1170.4-1993, places all of Bundaberg city within the highest earthquake hazard region of Queensland. Research into the earthquake hazard existing in the Bundaberg area (Turnbull 2001) suggests that the crustal stress gradient is such as to result in a relatively high risk, within the Australian context, of the recurrence of potentially damaging earthquakes, of relatively large magnitude; and, whilst it is probably true that all of Bundaberg is subject to the same regional hazard from earthquake occurrence, it can be demonstrated that similar structures in different parts of the city are not subject to the same relative risk to damage from the same earthquake event.

Macroseismic data collected subsequent to earthquakes that occurred within $120 \mathrm{~km}$ of Bundaberg in 1918 and in 1997 indicates that the surface foundation, on which Bundaberg is sited, has a tendency to amplify ground movement to varying degrees (Rynn 1985; Turnbull 2001). This variability of ground motion amplification can be attributed to differences in the nature and structure of the surface foundation layers. High amplification is associated with deep soils and unconsolidated materials. Amplification is also affected by the nature and structure of basement materials. Material interfaces that present a sharp gradient in shear wave propagation velocity can, depending on the interface geometry, reflect a considerable proportion of seismic energy (Field 1996; Dravinski et al 1996). Under conditions where the basement geometry is suitable, 


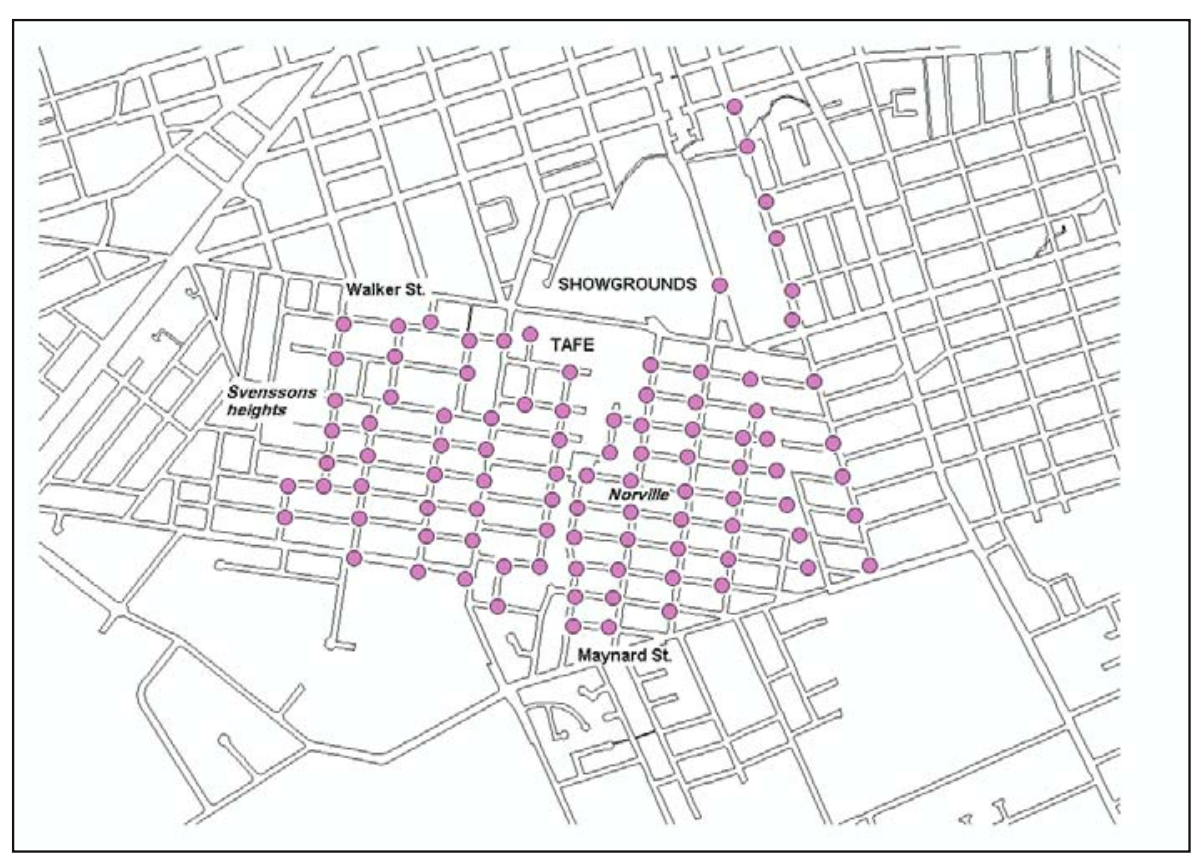

Figure 9. BBGA data collection sites.

considerable seismic energy resulting from reflected basin-edge-induced waves could conceivably be confined within a basin for extended time, after the initial waves have passed (Field 1996).

Given the relatively high earthquake hazard presented to Bundaberg city, and the observed vulnerability of the city to earthquake shaking, it was considered to be a suitable area in which to trial the relative seismic shaking vulnerability microzonation using the author's adaptation of the Nakamura horizontal to vertical spectral ratio method. The method was used to conduct a study into the distribution of horizontal ground movement pseudo-amplification in the Bundaberg city area. The results of this study have provided microzonation data that can be used to supplement Australian earthquake loading codes, such as AS1170.4-1993, providing refinement of the codes within Bundaberg.

\subsubsection{Data collection sites}

The field measurements were conducted in two separate episodes.

In the first episode, designated BBGA, 112 sites were occupied in the residential zone south of the Bundaberg TAFE College. Viable data was collected from 95 of the sites. The remaining sites were not viable due to operation abnormalities, such as non-levelling of the sensor or failing to realise that the recorder memory was full. The sites were chosen on street intersections or about $100 \mathrm{~m}$ apart. Figure 9 is a map depicting the viable sites occupied during the BBGA data collection episode.
Subsequent to the collection of the BBGA field data it was realized that coverage of the whole of the Bundaberg area at that resolution was impractical. Previous investigators (c.f., Gaul et al 1995) have indicated that grid spacing in the order of $3 \mathrm{~km}$ was sufficient for the purposes of microzonation. Other investigators (McCue and Love 1997) have demonstrated that irregular spacings of $1 \mathrm{~km}$ or less are sufficient to produce microzonation by means of mapped relative risk contours. As it was the intention of this current investigation to produce contoured risk maps of the area under investigation, it was decided to use a grid spacing of $1 \mathrm{~km}$.

In the second episode, designated BBGB, 88 viable sites were occupied, covering most of the Bundaberg city local government area. The sites were chosen as near as possible to the intersection of the $1000 \mathrm{~m}$ grid lines on the Hema Bundaberg street map (Hema 1997). Those potential sites already occupied during the BBGA episode were not reoccupied. Figure 10 is a map depicting the viable sites occupied during the BBGB data collection episode, and includes those BBGA sites that were suitable for inclusion in the BBGB dataset.

\subsubsection{Instrumentation}

All data collection was done using a combination of Kelunji classic seismograph and Sprengnether S6000 tri-axial seismometer. The analogue data processing boards in the Kelunji instruments used for data collection employ direct current coupling and are capable of recording signals in the range 


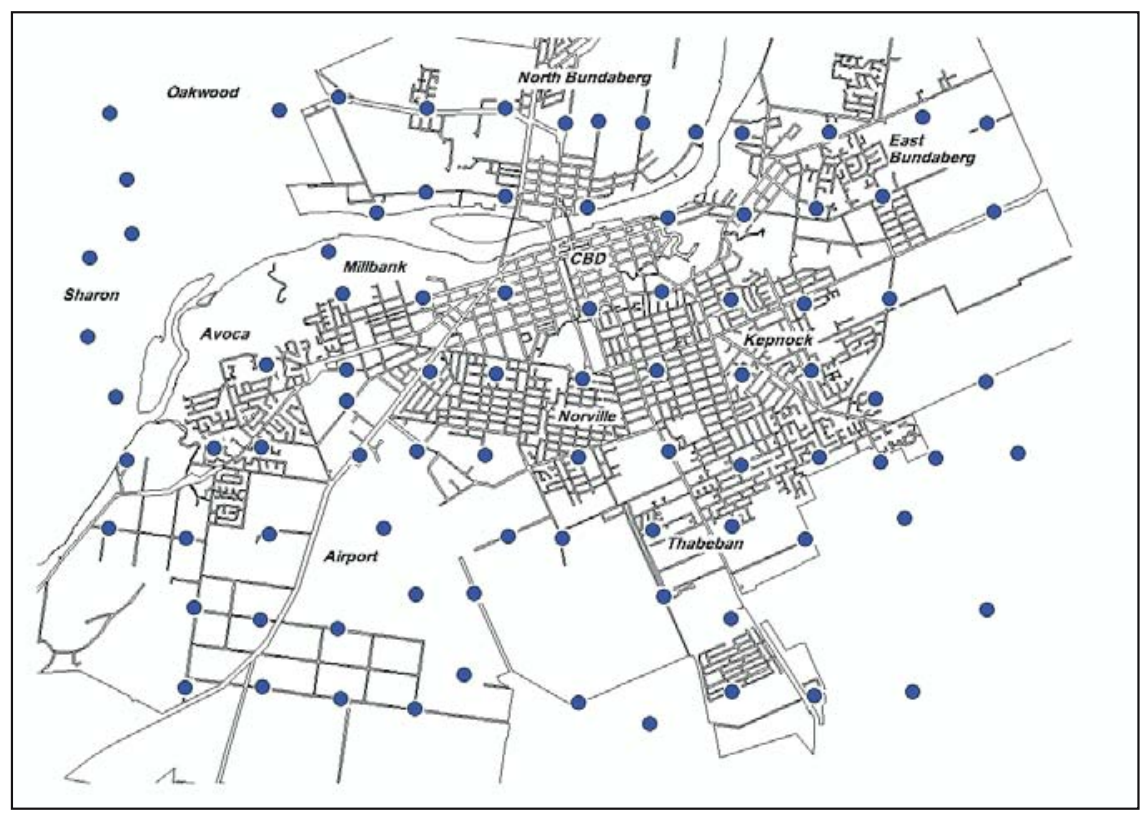

Figure 10. BBGB data collection sites.

from $0 \mathrm{~Hz}$ up to $25 \mathrm{~Hz}$, with a dynamic range in excess of $90 \mathrm{~dB}$ (Pers. Com. Adam Pascale, Seismic Research Centre, 26 March 2001; Appendix 1).

The output characteristic specification sheet for the S6000 (Appendix 2) indicates that this sensor provides a usable signal of 5 volts per $\mathrm{ms}^{-1}$ at $0.4 \mathrm{~Hz}$. This represents a reduction of $13.8 \mathrm{~dB}$ of voltage below the nominal level; well within the dynamic ranges of the Kelunji Classic analogue to digital features. Since a spectral ratio is employed for analysis the low frequency roll-off does not present a technical difficulty. The seismograph provides adequate signal down to at least $0.4 \mathrm{~Hz}$, thus the lower frequency of $0.5 \mathrm{~Hz}$ indicated in figure 8 is accurately achieved using this instrumentation.

During data collection the instrumentation was conveyed in the back of a vehicle. The vehicle's battery was used to power all instrumentation. A Garmin GPS 12XL was used to determine the geographical location of each site in terms of its longitude and latitude. A Suunto MC-1 compass, corrected for $10^{\circ}$ easterly deviation of magnetic north from true north, was used to orientate the sensor at each site. The Springnether S6000 triaxial seismic sensor is designed with an orientation arrow moulded into the housing. The manufacturers recommend that the instrument be installed with the arrow pointing due west, so as to ensure correct polarity of the horizontal sensors. At each site the arrow of the sensor was orientated to the west, except in cases where leveling of the sensor could not be achieved. Since the results of the microzonation were not dependent on the correct polarity of the horizontal sensors, in those rare instances the arrow was orientated to the east.
The data from the Kelunji Classic seismograph was downloaded to a Toshiba 220CDS laptop running the Microsoft ${ }^{\circledR}$ Windows95 ${ }^{\circledR}$ V4.00.950 B operating system, using Telix ${ }^{\circledR}$ V3.51 communications software for DOS ${ }^{\circledR}$ V3.1 or higher.

\subsubsection{Data analysis}

The micro-seismograms recorded at each of the data collection sites were analyzed in accordance with the microzonation methodology explained in section 2.3. This resulted in allocating each site with three microzonation earthquake loading site factors $\left(S_{M}\right)$, for low-rise, medium-rise and high-rise buildings, depending on the relative horizontal ground movement amplification exhibited at that site.

The ESRI ${ }^{\circledR}$ ArcMap $^{\text {TM }}$ 2D Spacial Analyst computer application was used to convert the $S_{M}$ value determined for each site to contoured earthquake shaking vulnerability zones by interpolation, and displayed on maps of the Bundaberg city area (see figures 11, 12 and 13). Manual analysis produces almost identical results but is more time consuming.

\subsubsection{Qualitative descriptions}

The boundaries between adjacent vulnerability zones depicted in figures 11,12 and 13 are approximate only, and may vary from the actual positions depicted. For explanatory purposes the qualitative descriptions listed in table 3 may be used.

In using these descriptions (and also the arbitrary $S_{M}$ values) it must be kept in mind that, 


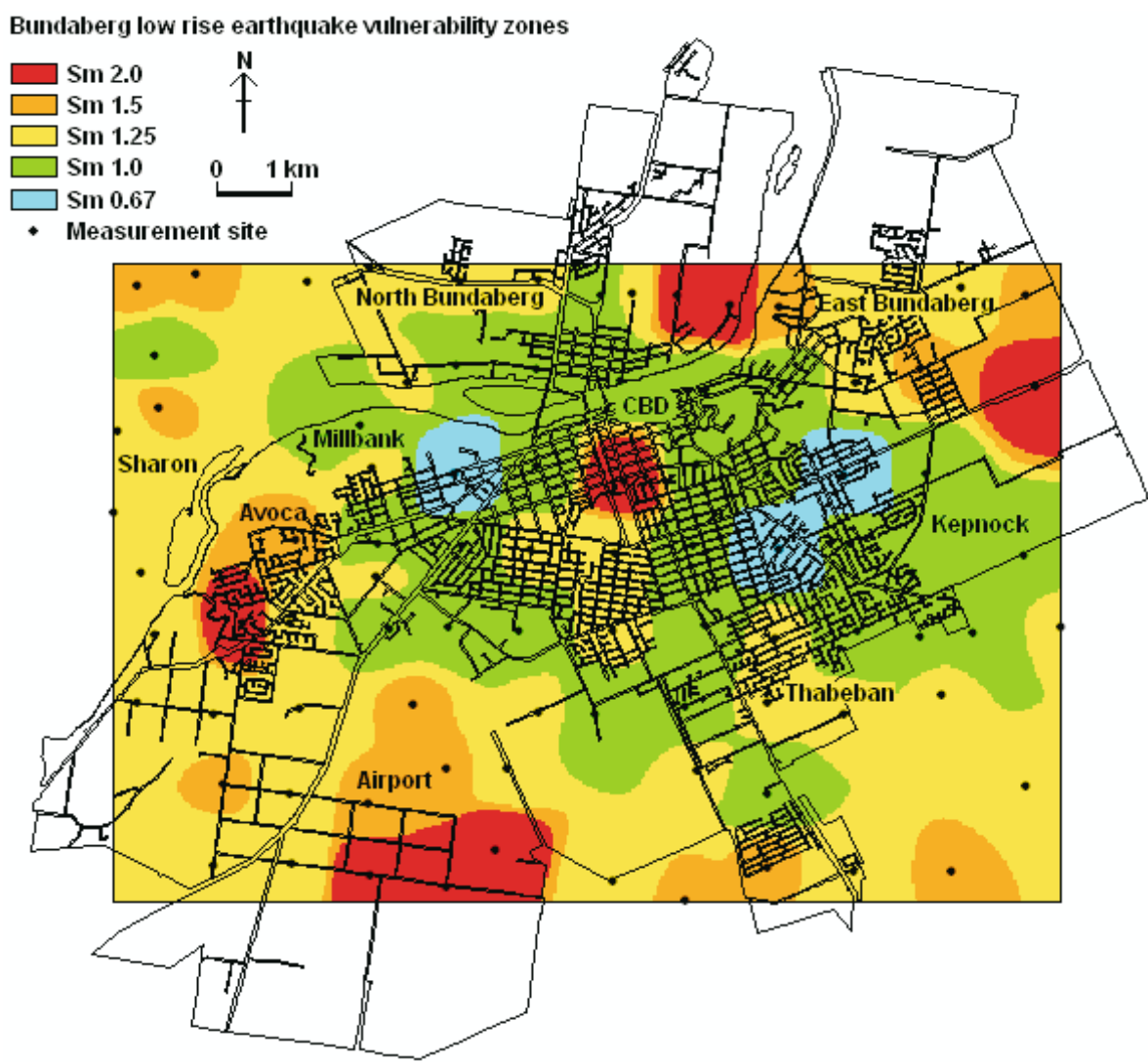

Figure 11. Bundaberg earthquake loading site factors for low-rise buildings.

whilst the relative vulnerability zones depicted in the microzonation maps are internally consistent within the source dataset (i.e., they are applicable within the Bundaberg city area), they cannot be used to compare the Bundaberg vulnerability zones with vulnerability zones derived for other areas, using a different spectral dataset.

\subsubsection{Commentary on common features of the maps}

The maps contained in figures 11,12 and 13 display colour coded earthquake zone vulnerability factors $S_{M}$. The colours blue, green, yellow, orange and red correspond to $S_{M}=0.67,1.0,1.25,1.5$ and 2.0 respectively. Commentary will be presented in qualitative terms.

All three maps display well-defined vulnerability zones superimposed on a background of moderate vulnerability. In the centre of the low-rise and highrise maps is a large moderately low to moderate zone extending east to west from Kepnock to Millbank, and north to south from north Bundaberg to Thabeban. This central zone is intersected NNE to SSW by a central corridor of higher value. The central zone is recognizable in the medium-rise map as two moderately low to moderate zones in the Kepnock and Millbank areas, with a wide separation of moderate vulnerability between them. The NNE to SSW central corridor of high values has apparent extensions in the areas of the Airport and the eastern part of north Bundaberg. These extensions appear on all three maps. There are five high value zones at the boundaries of the measurement area to the north, west and south that have counterparts identifiable on all three maps: Avoca/Sharon; the Airport; south Thabeban; east Bundaberg; and the east section of north Bundaberg.

\subsubsection{Commentary on features of the low-rise map}

The map shown in figure 11 displays several welldefined vulnerability zones superimposed on a background of moderate vulnerability. In the centre is a large moderately low to moderate zone extending east to west from Kepnock to Millbank, and north to south from north Bundaberg to Thabeban. This central zone encloses an oblong central island of higher values that separates two zones of low to moderately low to the east and west. The central island contains a moderately high to high core centred on the area just south of the central business district (CBD). The oblong central island of high values has apparent extensions in the areas of the Airport and the eastern part of north 


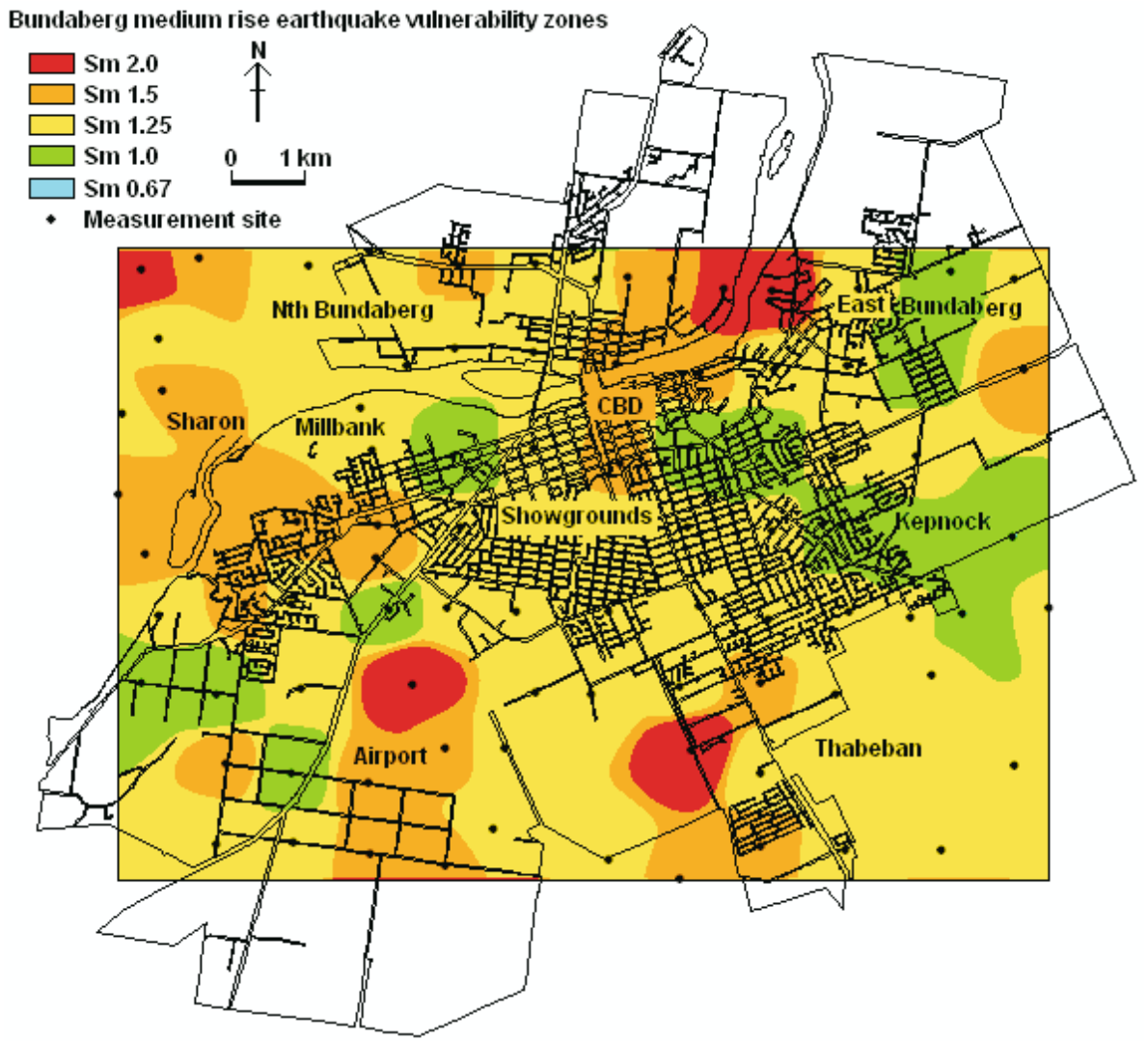

Figure 12. Bundaberg earthquake loading site factors for medium-rise buildings.

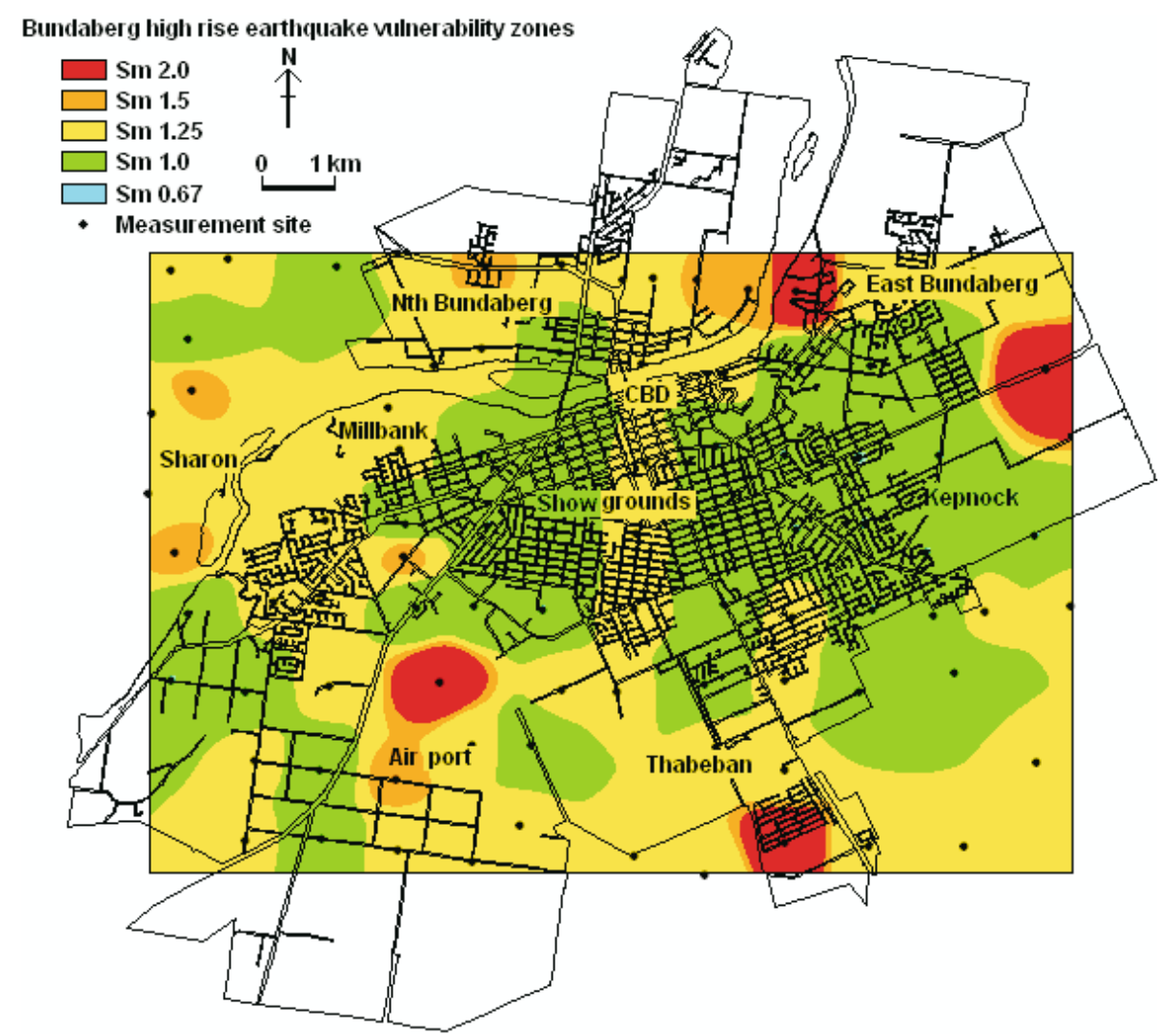

Figure 13. Bundaberg earthquake loading site factors for high-rise buildings. 
Table 3. Qualitative description of relative risk.

\begin{tabular}{ll}
\hline $\begin{array}{l}\text { Seismic microzonation } \\
\text { loading factor }\left(S_{M}\right)\end{array}$ & $\begin{array}{c}\text { Qualitative description } \\
\text { of relative seismic risk }\end{array}$ \\
\hline 0.67 & Low to moderately low \\
1.00 & Moderately low to moderate \\
1.25 & Moderate \\
1.50 & Moderate to moderately high \\
2.00 & Moderately high to high \\
\hline
\end{tabular}

Bundaberg. The central zone is framed by a series of high value zones to the north, west and south. The high value zones in the areas of Avoca/Sharon, the Airport, east Bundaberg and the east section of north Bundaberg exhibit core values of moderately high to high.

\subsubsection{Commentary on features of the medium-rise map}

The map shown in figure 12 displays several welldefined vulnerability zones superimposed on a background of moderate vulnerability. Distinctive features are the two high value zones thrusting into the central area of the map from the NNE and SSW. In the centre is a broad background area that separates one oblong moderately low to moderate zone (from Kepnock through almost to the CBD) in the east from another (from Millbank down to Sugarlands) in the west. The perimeter is flanked by a series of high value zones to the north, west and south. The high value zones in the areas of the Airport, south Thabeban, the east section of north Bundaberg and north Sharon exhibit core values of moderately high to high.

\subsubsection{Commentary on features of the high-rise map}

The map shown in figure 13 displays several welldefined vulnerability zones superimposed on a background of moderate vulnerability. In the centre are two moderately low to moderate central zones extending east to west from Kepnock to Millbank, and north to south from north Bundaberg to Thabeban separated by a background central corridor. The central zones are framed by a series of high value zones to the north, west and south. The high value zones in the areas of the Airport, south Thabeban, east Bundaberg and the east section of north Bundaberg exhibit core values of moderately high to high.

\section{Conclusions}

The seismic shaking vulnerability survey methodology described in this paper provides an effective practical alternative to computational intensive theoretical modelling of site response to earthquake, and time consuming test versus reference site horizontal ratio methods. The author concedes that alternative methods have advantages not exhibited by the method herein described. For example, the author's method cannot determine the absolute horizontal amplification factor at test sites, and it has limited ability to determine the unconsolidated substrate depth at test sites. Relative seismic shaking vulnerability microzonation using an adaptation of the Nakamura horizontal to vertical spectral ratio method provides the following advantages over alternative methods.

- Low cost. It does not require high speed computing facilities.

- Non-invasive. It does not require artificial seismic energy sources (i.e., explosions). There is no need to wait for natural seismic events.

- Low and flexible instrumentation requirements. A single seismometer and data logger of almost any type is required.

- Rapid field data collection phase. $100 \mathrm{~km}^{2}$ can easily be covered by a single operator in 5 days.

- Field data can be collected at any time during the day or night because the results are insensitive to ambient social noise.

- No basement rock reference site is required thus eliminating trigger synchronisation between reference and multiple test site seismographs.

- Insensitivity to ground-shaking resonance peaks thereby eliminating any reliance on resonance peaks for results interpretation.

- Rapid computer aided analysis using standard GIS software.

- The results have both intuitive town planning and practical engineering interpretation.

- The results can be presented as arbitrary quantitative relative values or as qualitative descriptions.

- The results obtained from non-contiguous survey fields can be relatively compared.

The resulting microzonation maps produced by this method indicate the relative seismic shaking risk for built structures of different height categories within adjacent zones, with a granularity of less than $1 \mathrm{~km}$.

\section{Acknowledgements}

The author acknowledges the assistance of Professor Bruce Boreham (Central Queensland University), and Adjunct Professor Kevin McCue (Geoscience Australia and Central Queensland University) in the development of the ideas presented in this paper. 


\section{Specifications}

The Kelunji Classic consists of a Power and Timing Board (KP1), a Computer Board (KC1), an Analogue Board (KA1 or KA2), and one to three Data Storage Modules (KI1). These are mounted in a double Euro-connector card frame within a powder coated stainless steel case (KF1). A KGB Module can be connected to facilitate GPS reception, phone and modem power regulation, low battery cut-off and external watchdog monitoring.

\section{KF1 - Housing}

Dimensions:

Mass:

Display LED's:

Connector LED's:

Controls:

\section{$280 \times 275 \times 200 \mathrm{~mm}$ typ $7.6 \mathrm{~kg}$}

Running, Error, Trigger, Modem, Insert Memory, Memory Half Full, Memory Full \& Disarmed.

Battery Low, Battery OK, Battery Fuse OK, Charger Fuse OK

LED enable,

Disarm/Trigger/Restart

\section{KP1 - Power \& Timing Board}

$\begin{array}{ll}\text { Operating Voltage: } & 11-15 \text { Volts } \\ \text { Charger Voltage: } & 12-18 \text { Volts } \\ \text { Charger Regulator: } & \text { Up to } 3 \mathrm{~A} \\ \text { Power Consumption: } & \text { typ. } 45 \mathrm{~mA} @ 12 \mathrm{~V} \\ \text { Crystal Accuracy: } & 0.2 \mathrm{ppm}, 0-50^{\circ} \mathrm{C} \text {, others available } \\ \text { Clock Sync.: } & \text { To logic level, relay closure or tone } \\ \text { Standby Crystal Acc.: } & 50 \mathrm{ppm}, 0-50^{\circ} \mathrm{C} \\ \text { Standby Battery Life: } & \text { typ. } 10 \text { years } \\ \text { Auxiliary Input: } & 0-5 \mathrm{~V}, 10 \text { bit precision } \\ \text { Auxiliary Outputs: } & 0-5 \mathrm{~V}, 8 \text { bit precision (std.) } \\ & 0-5 \mathrm{~V}, 12 \text { bit precision (opt.) } \\ & \text { Relay close for ext. radio or alarm }\end{array}$

Analogue Monitoring: 10 bit precision monitoring of voltages, currents, temperature etc.

\section{KC1 - Computer Board}

Power Consumption: typ. $30 \mathrm{~mA} @ 12 \mathrm{~V}$

Serial Interfaces: $\quad 2$ @ $300-38400$ baud

Alarms: $\quad 2$ logic level outputs

\section{KI1 - Internal Data Storage Board \\ Data Capacity: 1 MByte \\ Type: $\quad$ Battery backed CMOS \\ Battery Type: $\quad 3 V$ Lithium, 1.8Ah \\ Battery Life: $\quad 300$ days (continuous use) to 10 years (if never used) \\ Battery Monitor: Usage day counter \\ Power Consumption: typ. $1 \mathrm{~mA} @ 12 \mathrm{~V}$}

\section{KGB Module}

Quiescent Current:

Phone Power:

typ. 7mA @ 12V

Modem Power: $\quad$ Max 500mA (1) 12V

GPS Power: $\quad 140 \mathrm{~mA} @ 12 \mathrm{~V}$

Low Voltage Cut-Off: $\quad 11.0 \mathrm{~V} \pm 1 \%$

KA1 - 12 Bit Gain Ranging Analogue Board

No. of Channels: $\quad 1$ or 3

Anti-alias Filter: $\quad$ 4th order Bessel @ 25Hz (std.) Butterworth filter and other antialias frequencies optional

Pre-amp Gain: $\quad$ x1 (std.) to $\times 10$ (H/W selectable)

Coupling: $\quad \mathrm{DC}$ or $\mathrm{AC} @ 0.2 \mathrm{~Hz}$ (std.)

Resolution: 12 bit

Active Gain Ranging: 12 stages, $x 1$ to $\times 2048$

Dynamic Range: $\quad 130+d B$

Sample Rate: $\quad 8$ to 250 sps (S/W selectable)

Power Consumption: typ. $30 \mathrm{~mA} @ 12 \mathrm{~V}$

Transducer Power: $\quad+12 \mathrm{~V}, 250 \mathrm{~mA}$ and $\pm 15 \mathrm{~V}, 150 \mathrm{~mA}$

Input:

Single ended

Calibration: Step or sine, voltage or current

KA2 - 16 Bit Linear Analogue Board

No. of Channels: $\quad 1$ to 6

Anti-alias Filter: $\quad$ 7th order Bessel @ $50 \mathrm{~Hz}$ (std.) Butterworth filter and other antialias frequencies optional

Pre-amp Gain: $\quad 1,10$ or 100 (H/W selectable) $1,2,4$ or 8 ( $\mathrm{S} / \mathrm{W}$ selectable)

Coupling: $\quad$ DC or AC $@ 0.1 \mathrm{~Hz}$ (std.)

Resolution: 16 bit

Dynamic Range: $\quad 90+\mathrm{dB}$

Sample Rate: $\quad 64$ to 400 (S/W selectable) (std.) Up to 2000 (opt.)

Power Consumption: typ. $40 \mathrm{~mA} @ 12 \mathrm{~V}$ for 3 channel typ. $50 \mathrm{~mA} @ 12 \mathrm{~V}$ for 6 channel

Transducer Power: $\quad+12 \mathrm{~V}, 250 \mathrm{~mA}$ and $\pm 15 \mathrm{~V}, 150 \mathrm{~mA}$

Input: Differential

Calibration:
Step, square, sine, swept sine or pseudo-random, voltage or current 


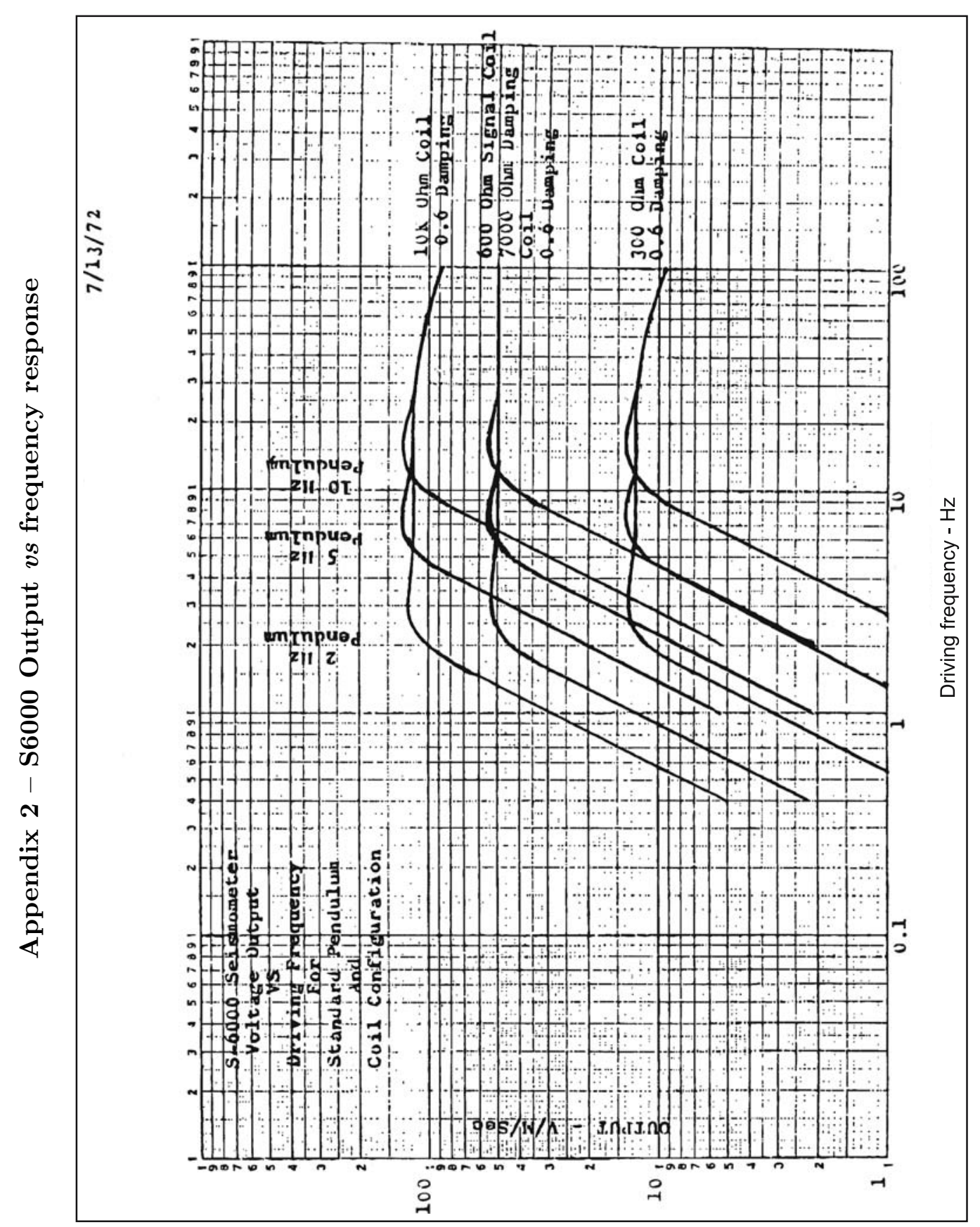




\section{References}

Bragato P L and Slejko D 2005 Empirical Ground-Motion Attenuation Relations for the Eastern Alps in the Magnitude Range 2.5-6.3; Bull. Seismol. Soc. Am. 95(1) $252-276$.

Chávez-García F J, Sánchez L R and Hatzfeld D 1996 Topographic Site Effects and HVSR. A Comparison Between Observations and Theory; Bull. Seismol. Soc. Am. 86(5) 1559-1573.

Chávez-García F J, Rodríguez M, Field E H and Hatzfeld D 1997 Topographic site effects. A comparison of two nonreference methods; Bull. Seismol. Soc. Am. 87(6) 1667-1673.

Chávez-García F J, Domínguez T, Rodríguez M and Pérez F 2007 Site Effects in a Volcanic Environment: A Comparison between HVSR and Array Techniques at Colima, Mexico; Bull. Seismol. Soc. Am. 97(2) 591-604.

Clitheroe G M and Taber J J 1995 Assessing earthquake site response using Microtremors: A case study in Wellington City, New Zealand; Pacific Conference on Earthquake Engineering, Australia, 20-22 November, 1995.

Coutel F and Mora P 1998 Simulation-based comparison of four site-response estimation techniques; Bull. Seismol. Soc. Am. 88(1) 30-40.

Cuthbertson R, Winter M and Jaume S 1998 Preliminary results of Brisbane microtremor survey; Australian Earthquake Engineering Society, Proceedings of the 1998 Conference, Perth, Western Australia, Paper 12, 1998. ISBN 0-7340-1442-2. (Also presented at the 2nd Annual AGSO Cities Project Workshop, Townsville, 8 July 1998.)

Darragh R B and Shakal A F 1991 The Site Response of Two Rock and Soil Station Pairs to String and Weak Ground Motion; Bull. Seismol. Soc. Am. 81(5) 1885-1899.

Dimitriu P P, Papaioannou Ch A and Theodulidis N P 1998 EURO-SEISTEST Strong-Motion Array near Thessaloniki, Northern Greece: A Study of Site Effects; Bull. Seismol. Soc. Am. 88(3) 862-873.

Dravinski M, Ding G and Wen K-L 1996 Analysis of Spectral Ratios for Estimating Ground Motion in Deep Basins; Bull. Seismol. Soc. Am. 86(3) 646-654.

Drouet S, Souriau A and Cotton F 2005 Attenuation, Seismic Moments, and Site Effects for Weak-Motion Events: Application to the Pyrenees; Bull. Seismol. Soc. Am. 95(5) 1731-1748.

Ferretti G, Massa M, Isella L and Eva C 2007 SiteAmplification Effects Based on Teleseismic Wave Analysis: The Case of the Pellice Valley, Piedmont Italy; Bull. Seismol. Soc. Am. 97(2) 605-613.

Ferritto J M 1996 Repeatability of Microseism Measurements in Port Hueneme Case Study; Bull. Seismol. Soc. Am. 86(2) 428-435.

Field E H and Jacob K H 1995 A Comparison and Test of Various Site-Response Estimation Techniques, Including Three That Are Not Reference-Site Dependent; Bull. Seismol. Soc. Am. 85(4) 1127-1143.

Field E H 1996 Spectral Amplification in a Sediment-Filled Valley Exhibiting Clear Basin-Edge-Induced Waves; Bull. Seismol. Soc. Am. 86(4) 991-1005.

Gaull B A, Kagami H and Taniguchi H 1995 The Microzonation of Perth, Western Australia, Using Microtremor Spectral Ratios; Earthquake Spectra 11(2) 173-191.

Hema 1997 Bundaberg including Bargara, Elliott Heads, Burnett Heads and Moore Park, Hema Maps Pty. Ltd., $3^{\text {rd }}$ edn.

Jensen V H 2000 Seismic microzonation in Australia; J. Asian Earth Sci. 18(1) 3-15.
Jones T, Laume S, Granger K, Scott G and Cuthbertson R 1998 Earthquake risk in Cairns: A pilot study, Australian Earthquake Engineering Society, Proceedings of the 1998 Conference, Perth, Western Australia, Paper 11, 1998. ISBN 0-7340-1442-2. (Also in QUAKES Report \#3, October 1998.)

Kagami H, Okada S, Shiono K, Oner M, Dravinski M and Mal A K 1986 Observation of 1-5-second Mocrotremors and their Application to Earthquake Engineering. Part III. A Two-Dimensional Study of Stie Effects in the San Fernando Valley; Bull. Seismol. Soc. Am. 76(6) 1801-1812.

Konno K and Ohmachi T 1998 Ground-Motion Characteristics Estimated from Spectral Ratio between Horizontal and Vertical Components of Microtremor; Bull. Seismol. Soc. Am. 88(1) 228-241.

Lachet C, Hatzfeld D, Bard P-Y, Theodulidis N, Papaioannou C and Savvaidis A 1996 Site effects and microzonation in the city of Thessaloniki (Greece) comparison of different approaches; Bull. Seismol. Soc. Am. 86(6) 1692-1703.

Lermo J and Chávez-García F J 1993 Site Effect Evaluation Using Spectral Ratios with Only One Station; Bull. Seismol. Soc. Am. 83(5) 1574-1594.

Lermo J and Chávez-García F J 1994 Are Microtremors Useful in Site Response Evaluation?; Bull. Seismol. Soc. Am. 84(5) 1350-1364.

McCue K F and Boreham B W 1996 Microzonation for an earthquake risk assessment at Rockhampton Queensland and implications for AS1170.4; Australian Cival/Structural Engineering Transactions CE39(1) 365-376.

McCue K and Love D 1997 Microtremor Survey of Adelaide, Australian Earthquake Engineering Society, Proceedings of the 1997 Conference, Brisbane, Queensland, Paper 19, 1997. ISBN 0-7325-1072-4.

Malagnini L, Tricarico P, Rovelli A, Herrmann R B, Opice S, Biella G and Franco R de 1996 Explosion, Earthquake, and Ambient Noise Recordings in a Pliocene SedimentFilled Valley: Inferences on Seismic Response Properties by Reference- and Non-Reference-Site Techniques; Bull. Seismol. Soc. Am. 86(3) 670-682.

Michael-Leiba M and Jensen V 1999 Seismic Microzonation of Launceston, Tasmania; Australian Geological Survey brochure, undated Circa 1999.

Milana G, Barba S, Del Pezzo E and Zambonelli E 1996 Site Response from Ambient Noise Measurements: New Perspectives from an Array Study in Central Italy; Bull. Seismol. Soc. Am. 86(2) 320-328.

Nakamura Y 1989 A Method for Dynamic Characteristics Estimation of Subsurface using Microtremor on the Ground Surface; Quarterly Report of Railway Technical Research Institute 30(1) 25-33.

Rynn J M W 1985 A Reapraisal of Queensland's Largest Known Earthquake - The "Queensland" Earthquake of 6 June 1918, Magnitude ML 6.2, Private Paper, Circa $1985-86$

SAA 1993(a) AS 1170.4-1993 Minimum design loads on structures (known as the SAA Loading Code) Part 4: Earthquake loads, Standards Association of Australia, 1993. ISBN 0-7262-8297-9.

SAA 1993(b) AS 1170.4 Supp1-1993 Minimum design loads on structures (known as the SAA Loading Code) Part 4: Earthquake loads Commentary (Supplement to AS 1170.4-1993), Standards Association of Australia, 1993. ISBN 0-7262-8298-7.

Schlindwein V and Koch K 2003 A Quantitative Study of the Site Effects Observed at the GERESS Array; Bull. Seismol. Soc. Am. 93(3) 1051-1064. 
Seekins L C, Wennerberg L, Margheriti L and Liu H-P 1996 Site Amplification at Five Locations in San Francisco, California: A Comparison of S Waves, Codas, and Microtremors; Bull. Seismol. Soc. Am. 86(3) 627-635.

Seht M I-V and Wohlenberg J 1999 Microtremor Measurements Used to Map Thickness of Soft Sediments; Bull. Seismol. Soc. Am. 89(1) 250-259.

Somerville M R, Kagami H and McCue K F 1993 Seismic Amplification Determined from Microtremor Monitoring at Alluvial and Rock Sites in Newcastle; Bulletin of the New Zealand National Society for Earthquake Engineering 26(2) 175-184.

Steidl J H, Tumarkin A G and Archuleta R J 1996 What is a Reference Site?; Bull. Seismol. Soc. Am. 86(6) 1733-1748.

Theodulidis N, Bard P-Y, Archuleta R and Bouchon M 1996 Horizontal-to-Vertical Spectral ratio and Geological Conditions: The Case of Garner Valley Downhole Array in Southern California; Bull. Seismol. Soc. Am. 86(2) 306-319.

Turnbull M L 2001 A Seismic Hazard Assessment and Microzonation of Bundaberg; Master's Thesis, Central Queensland University, Faculty of Engineering and Physical Systems, Published online, April 2001. Available online at http://seismo.cqu.edu.au/ CQSRG/staff/MikeT/publications/BundyMZ.pdf. Accessed 24 September 2007.

Wen K-L, Beresnev I G and Yeh Y T 1995(a) Investigation of non-linear site amplification at two downhole strong ground motion arrays in Taiwan; Earthquake Engineering and Structural Dynamics 24(3) 313-324, John Wiley \& Sons Ltd.

Wen K-L, Peng H-Y, Lui L-F and Shin T-C 1995(b) Basin Effects Analysis from a Dense Strong Motion Observation Network; Earthquake Engineering and Structural Dynamics 24(8) 1069-1083, John Wiley \& Sons Ltd. 